\title{
Original
}

\section{Effect of phototherapy on the metabolism of Streptococcus mutans biofilm based on a colorimetric tetrazolium assay}

\author{
Grace F. Gomez¹, Ruijie Huang2), George Eckert3), and Richard L. Gregory1) \\ 1)Department of Biomedical and Applied Sciences, Indiana University School of Dentistry, \\ Indianapolis, IN, USA \\ 2)Department of Pediatric Dentistry, West China School of Stomatology, Sichuan University, \\ Sichuan, P. R. China \\ ${ }^{3)}$ Department of Biostatistics, Indiana University School of Medicine, Indianapolis, IN, USA
}

(Received May 24, 2017; Accepted August 21, 2017)

\begin{abstract}
The aim of this in vitro study was to determine the effect of violet-blue light on the metabolic activity of early Streptococcus mutans biofilm, reincubated at 0,2 , and $6 \mathrm{~h}$ after $5 \mathrm{~min}$ of violet-blue light treatment. $S$. mutans UA159 biofilm cells were cultured for 12 to $16 \mathrm{~h}$ in microtiter plates with Tryptic Soy broth (TSB) or TSB with $1 \%$ sucrose (TSBS) and irradiated with violet-blue light for $5 \mathrm{~min}$. After irradiation, the plates were reincubated at $37^{\circ} \mathrm{C}$ for 0,2 , or $6 \mathrm{~h}$ in $5 \% \mathrm{CO}_{2}$. Colorimetric tetrazolium salt reduction assay was used to investigate bacterial metabolic activity. Mixed model ANOVA was used to find the difference between the violet-blue light treated and nontreated groups. Bacterial metabolic activity was significantly lower in the violet-blue light group for TSB than in the nontreated group $(P$ $<0.0001)$ regardless of recovery time. However, the differences between metabolic activity in the treated groups without sucrose decreased over time. For TSBS, metabolic activity was significantly lower with violet-blue light at 0 and $2 \mathrm{~h}$. Violet-blue light inhibited the metabolic activity of $S$. mutans biofilm cells in the light-treated group. This finding may present a unique treatment method for patients with active caries.
\end{abstract}

Correspondence to Dr. Richard L. Gregory, Department of Biomedical and Applied Sciences, Indiana University School of Dentistry, 1121 West Michigan St., Indianapolis, IN 46202, USA E-mail: rgregory@iu.edu

doi.org/10.2334/josnusd.17-0203

DN/JST.JSTAGE/josnusd/17-0203
Keywords Streptococcus mutans; violet-blue light; biofilm; XTT assay.

\section{Introduction}

Oral biofilm, or dental plaque, composed of a group of microorganisms, is the primary cause of dental caries. Among them, Streptococcus mutans is a cariogenic bacterium with the ability to form a biofilm. Various preventive treatments are currently used and have been shown to reduce, inhibit, and even eliminate oral biofilm. Noninvasive phototherapy/photodynamic therapy is an alternative therapeutic approach currently studied in the treatment of microbial infections to prevent the emergence of antibiotic-resistant bacterial strains. It is also under study in various disciplines as wound healing, tissue regeneration $(1,2)$, cancer therapy (3), and skin disorders $(3,4)$ as well as in the prevention of caries and oral infections (5). This light therapy is widely applied to control biofilms with and without an exogenous photosensitizer (5-7). Although photodynamic therapy employing exogenous photosensitizers are widely studied to control oral biofilm, investigations related to photodynamic therapy using endogenous photosensitizers are developing rapidly $(8,9)$.

Although visible light $(380-700 \mathrm{~nm})$ is commonly used to inhibit or kill bacteria $(5,10)$, the reduction rate was statistically significant when treated with only blue light (400-500 nm; $10 \mathrm{~min})$ (11). The synergistic effect of 20 -s blue light treatment with hydrogen peroxide reduced the bacterial growth up to $96 \%$ (11). Whereas a delayed antibacterial effect $(12,13)$ was reported by 


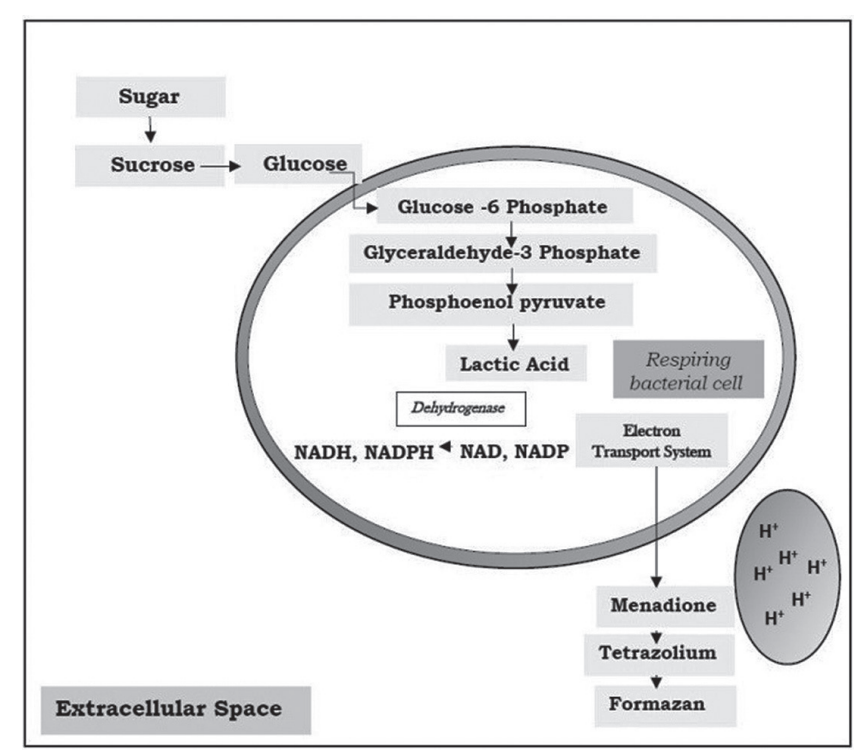

Fig. 1 S. mutans metabolizes carbohydrates including sucrose, glucose, lactose fructose, and other intermediates of sugars to generate energy. The glycolytic metabolic pathway includes various intermediates such as glucose-6-phosphate, glyceraldehyde 3-phosphate, phosphoenol pyruvate, and finally pyruvate. Pyruvate is converted to end-products such as lactic acid, acetate, formate, and ethanol. Enzymes such as various dehydrogenases are involved in S. mutans metabolism. The respiring bacterial cells produce NADPH during fermentation, which gets oxidized in addition to ATP by conversion of pyruvate to acetate, and the hydrogen ions are accepted by tetrazolium salt (XTT), which is further converted to a colored formazan compound.

Feuerstein et al. (11) in an S. mutans biofilm grown for $6 \mathrm{~h}$, whereas Chebath et al. (14) observed increased antibacterial effect after 3-, 5-, 7-, and 10-min treatment (13). Photoinactivation of $S$. mutans biofilm has been achieved through a 5 -min treatment with violet-blue light with a peak wavelength of $405 \mathrm{~nm}$ (15). This study reported the effect of violet-blue light on biofilm formation, colony forming units, and growth kinetics of S. mutans. However, the effect of violet-blue light treatment on the metabolic activity of $S$. mutans biofilm has not been examined. Determining the metabolic activity of S. mutans will directly demonstrate the overall vitality of S. mutans after exposure to violet-blue light and indirectly assess the viability of the bacterial cells. Although we have quantified bacterial cell numbers after treatment with violet-blue light, the metabolic activity assay used provides a measure of the respiratory activity of the inactivated bacterial cells. Metabolic activities such as biological oxidation of sugars or carbohydrates are vital for the survival of $S$. mutans (16), including respiration and fermentation (Jurtshuk P Jr. Bacterial metabolism, Baron S ed, Medical Microbiology, Galveston, 1996), resulting in the generation of high energy compounds adenosine triphosphate (ATP) and adenosine diphosphate (ADP).

S. mutans, being a saccharolytic organism, uses heterotrophic metabolism to generate energy. End products such as lactic acid, acetate, formate, and ethanol are produced during bacterial fermentation of sugars. Enzymes such as various dehydrogenases are involved in $S$. mutans metabolism (Fig. 1). The chemical reactions in the metabolism of a bacterial cell are vital for the division, replication, viability, and growth of S. mutans (13). The aim of this in vitro study was to determine the effect of violet-blue light on metabolic activity using a 2,3-bis(2-methoxy-4-nitro5 -sulfophenyl)- $2 H$-tetrazolium-5-carboxanilide (XTT) reduction assay on pre-cultured $S$. mutans biofilm, which was reincubated for 0,2 , or $6 \mathrm{~h}$ after $5 \mathrm{~min}$ of violet-blue light treatment.

\section{Materials and Methods}

\section{Bacterial strain, media and culture conditions}

Bratthall serotype $c$ strain S. mutans UA159 (ATCC 700610) obtained from American Type Culture Collection (Rockville, MD, USA) was used in this study. The strain was stored at $-80^{\circ} \mathrm{C}$ in $20 \%$ glycerol and grown in mitis-salivaris sucrose bacitracin (MSSB, Anaerobe Systems, Morgan Hill, CA, USA) agar plates. Liquid broth cultures were prepared with $5 \mathrm{~mL}$ of tryptic soy broth (TSB, Acumedia, Baltimore, MD, USA) and incubated for $24 \mathrm{~h}$ in a $5 \% \mathrm{CO}_{2}$ incubator. S. mutans was grown in TSB without sucrose and in TSB supplemented with $1 \%$ sucrose (TSBS) as a biofilm in sterile 96-well flat bottom microtiter plates (Fisher Scientific, Co., Newark, DE, USA). The biofilm cells were incubated for 12 to $16 \mathrm{~h}$ in a $5 \% \mathrm{CO}_{2}$ incubator for the cells to reach the logarithmic phase of growth.

\section{Light source}

Quantitative light-induced fluorescence (QLF, Inspektor Research Systems, Amsterdam, The Netherlands), a caries-detection system was used in this study. The system is equipped with a 35-watt xenon arc lamp and a 370-nm blue light filter and has a spectral wavelength ranging from 380 to $450 \mathrm{~nm}$ and a peak excitation wavelength of $405 \mathrm{~nm}$.

\section{Reagents}

"XTT (2,3-bis(2-methoxy-4-nitro-5-sulfophenyl)-2 $H$-tetrazolium-5-carboxanilide) sodium salt (Sigma-Aldrich, St. Louis, Missouri, USA) was used to detect metabolically active cells. Menadione (2-methyl-1, 4-naphthoquinone or vitamin $\mathrm{K}_{3}$ ), an electron transporter, was used 


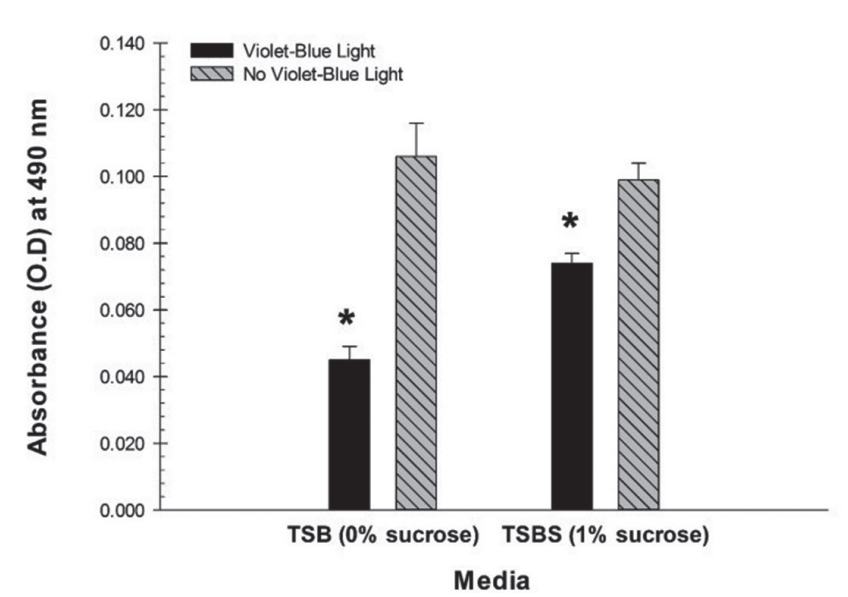

Fig. 2 At $0 \mathrm{~h}$, in both the TSB- and TSBS-grown S. mutans, the metabolic activity was significantly lower in the light-treated group compared with the nontreated group $(P<0.0001 ; P<$ $0.0001)$. Significance level was kept at $5 \%$. Asterisks represent significant differences $(P<0.05)$ between the light and no-light groups. Mean $\pm \mathrm{SE}$.

as an electron-coupling activator to reduce XTT to an orange-colored Tetrazolium Red Formazan (1-phenyl2-[phenyl(2-phenylhydrazinylidene) methyl] diazene) in metabolically active cells.

\section{Colorimetric tetrazolium assay for metabolic activity} S. mutans was grown in $200 \mu \mathrm{L}$ of either TSB or TSBS by pipetting $190 \mu \mathrm{L}$ of TSB or TSBS and $10 \mu \mathrm{L}$ of an overnight culture into each well. S. mutans biofilm cells were grown in 96-well microtiter plates with a 1-well gap between the samples so that the light targeting a given well does not impact surrounding wells. Before irradiation with violet-blue light, the supernatant or planktonic medium was removed. The wet biofilm was continuously irradiated with violet-blue light for 5 min at a fixed distance of $2 \mathrm{~cm}$ from the biofilm. After irradiation, $0.9 \%$ saline was added to the wells and the plates were either not reincubated or reincubated for 2 or $6 \mathrm{~h}$ after addition of TSB and TSBS, respectively. The metabolic activity of the treated biofilm cells was determined using an adaptation (17) of the method developed originally by Pierce et al. (18). XTT sodium salt solution was freshly prepared and activated with menadione. The $S$. mutans biofilm cells were gently washed twice with $0.9 \%$ saline, then $200 \mu \mathrm{L}$ of the XTT solution was added, covered with aluminum foil, and incubated for $2 \mathrm{~h}$ in a dark environment at $37^{\circ} \mathrm{C}$. The supernatant was removed and pipetted into another 96-well microtiter plate and measured for absorbance at $490 \mathrm{~nm}$.

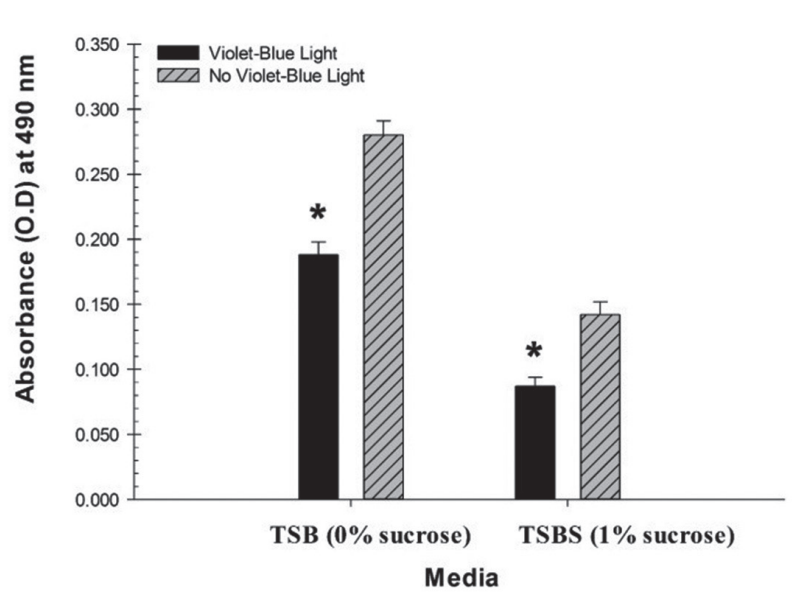

Fig. 3 At 2 h, in both the TSB- and TSBS-grown S. mutans, the metabolic activity of the light-treated group was significantly lower compared with the nontreated group $(P<0.0001 ; P<$ $0.0001)$. Significance level was kept at $5 \%$. Asterisks represent significant differences $(P<0.05)$ between the light and no-light groups. Mean $\pm \mathrm{SE}$.

\section{Statistical analysis}

The metabolic activity determined by the XTT assay and the effect of violet-blue light on S. mutans and the nontreated control group based on various recovery time periods of 0,2 , and $6 \mathrm{~h}$ were analyzed separately based on the growth medium without sucrose (TSB) and with $1 \%$ sucrose (TSBS) using mixed-model ANOVA, which included fixed effects for the treated and nontreated groups of violet-blue light, time periods of reincubation, and effect of light-by-time-period interaction and a random effect for each experiment. Pair-wise comparisons were made using Fisher's protected least-significant differences to control the significance level at 5\%. Analyses were performed on the log-transformed data.

\section{Results}

The effect of light with respect to recovery time was significant both in the absence (TSB) and in the presence of sucrose (TSBS; $P<0.0001$ ). The metabolic activity of TSB-grown $S$. mutans cells treated with violet-blue light was significantly lower than the nontreated group regardless of the recovery time ( $P<0.0001 ; 0$ h, Fig. $2 ; 2$ h, Fig. 3 ; and 6 h, Fig. 4). The decreasing differences between XTT and with and without light show that the effect of violet-blue light decreased as recovery time increased. The metabolic activity was significantly decreased at 0 h compared with a 2 -h $(P=0.0021$; Fig. 3$)$ and a 6 -h recovery period $(P=0.0012$; Fig. 4$)$. The metabolic activity was not significantly different from each other $(P=0.90)$ after the 2-h and 6-h recovery periods.

The metabolic activity of TSBS-grown $S$. mutans 


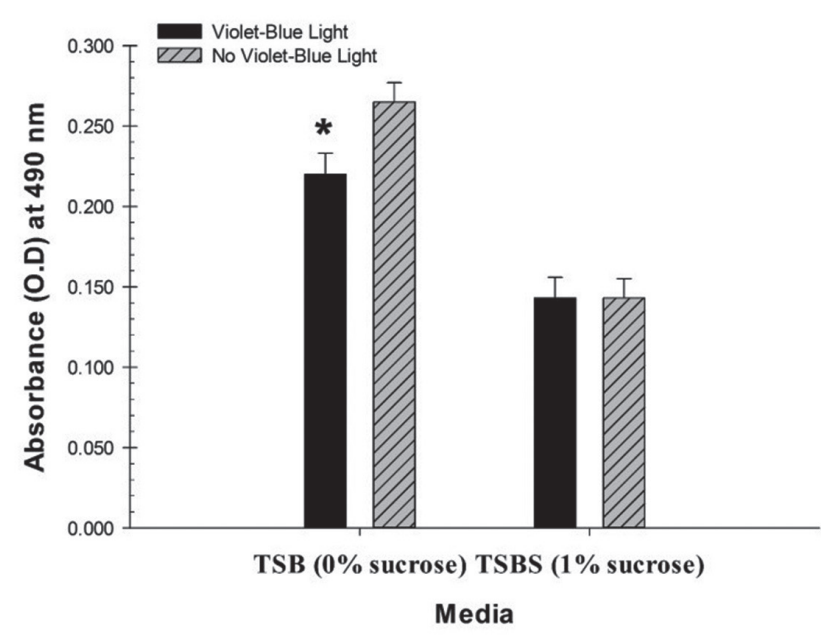

Fig. 4 At 6 h, in the TSB-grown $S$. mutans group, the metabolic activity was significantly lower in the light-treated group compared with the nontreated group $(P<0.0001)$. In the TSBSgrown $S$. mutans group, the metabolic activity of the light-treated group and the nontreated group was not significantly different $(P$ $=0.30)$. Significance level was kept at 5\%. Asterisks represent significant differences $(P<0.05)$ between the light and no-light groups. Mean $\pm \mathrm{SE}$.

treated with violet-blue light was significantly lower $(P$ $<0.0001)$ than the nontreated control group (Fig. 2) at recovery periods of $0 \mathrm{~h}$ and $2 \mathrm{~h}(P<0.0001$; Fig. 3). However, the difference was not significant at the 6-h recovery period ( $P=0.30$; Fig. 4$)$. For TSBS-grown $S$. mutans, regardless of light treatment, there was no significant effect due to recovery time $(P=0.66)$.

\section{Discussion}

In our previous study, we demonstrated photoinactivation of $S$. mutans with 5 min of violet-blue light treatment by quantitatively determining the viability (colony-forming units) of biofilm cells (15). In this study, we found decreased metabolic activity of violet-blue light-treated S. mutans at 0 -h and 2-h recovery periods, providing an indirect estimation of cell viability. The metabolic activity of TSBS S. mutans remained unaffected after 6-h recovery period and was increased compared with 0 -h recovery period. We previously reported that there was no difference in biofilm formation with respect to light treatment after the 6-h reincubation period in the TSBS group, which suggests that the bacterial cells are viable (15). Bacterial cells, however, which are encompassed within extracellular glucans, may be improperly reduced by tetrazolium salts (19) in the assay used in this study. This suggests the significant reduction of bacterial cells in TSB compared with TSBS as the microcolonies protect S. mutans from violet-blue light. The respiring bacterial cells produce NADH, and the hydrogen ions are accepted by tetrazolium salt (XTT), which is further converted to a colored formazan compound (20). Compared with 0 $\mathrm{h}$, both 2- and 6-h recovery periods produced increased metabolic activity. The biofilm formed at baseline of 0 $\mathrm{h}$ became viable at 2 and $6 \mathrm{~h}$, and the biofilm formed correlated with the time of reincubation. The violet-blue light-treated groups, however, produced reduced metabolic activity compared with the nontreated group.

There was some impairment in the chemical reactions responsible for metabolizing carbohydrate sources after violet-blue light treatment contributing to the inhibition of metabolic activities in S. mutans biofilm cells seen in this study. The pathogenic nature of cariogenic biofilm is determined by metabolic activity (21). Dehydrogenases in bacterial cells play a vital role in metabolic activities. Hydrogen ions from NADPH are accepted by artificial electron transporting reagents such as menadione, and the electrons are transferred to the resulting tetrazolium salt. The colorless XTT compound can enter bacterial cells through intact cell walls and membranes through a redox process and be converted into orange formazan derivatives. Formazan, formed in the culture supernatant, is a water-soluble compound, and can be measured by absorbance measurements. Quantification of bacterial cell number and correlation with the colored signal may be a better option. However, photoinactivated bacterial cells that are not viable, but metabolically active, cannot be determined through colony counting. The efficacy of violet-blue light through use of a colorimetric method for assessing the metabolic activity helps to design future studies such as determining the expression of virulence factors associated with biofilm formation and the efficacy of violet-blue light on S. mutans biofilm grown on human enamel or dentin specimens.

Five minutes of irradiation time is longer than that for at-home procedures. Irradiation could be done as a part of prophylactic treatment in a dental clinic; however, patient noncompliance with the at-home procedure could be a potential disadvantage. Determination of the minimum irradiation time necessary to inhibit $S$. mutans biofilm formation should be conducted in future studies. This will potentially help to reduce the irradiation time in minutes. Effectiveness of blue light after 20, 30, and 60 s cannot be achieved with only violet-blue light, as seen in the presence of exogenous photosensitizers. There is also recovery of biofilm after 2 and $6 \mathrm{~h}$, suggesting that repeated treatments may be necessary to prevent the regrowth of biofilm. Within the limitations of this study, more innovative approaches are needed.

The metabolic activity of $S$. mutans was significantly 
reduced in the violet-blue light-treated group compared with the nontreated group immediately after treatment. However, there was some recovery of the biofilm cells after treatment with violet-blue light. Although the bacterial cells were inactivated immediately, the respiratory capacity of the bacteria was not affected after $6 \mathrm{~h}$ of treatment in the presence of sucrose, suggesting that repeated violet-blue light treatment is highly recommended for the prevention and control of oral biofilms to prevent dental caries. Violet-blue light at home and in clinical settings could serve as an adjunct prophylactic treatment in controlling the bacterial numbers based on its significant inhibitory effect for a longer period in the absence of sucrose.

\section{Conflict of interest}

None declared.

\section{References}

1. Hamblin MR, Demidova TN (2006) Mechanisms of low level light therapy. Proc SPIE 6140.

2. Chaves ME, Araujo AR, Piancastelli AC, Pinotti M (2014) Effects of low-power light therapy on wound healing: LASER $x$ LED. An Bras Dermatol 89, 616-623.

3. Gursoy H, Ozcakir-Tomruk C, Tanalp J, Yilmaz S (2013) Photodynamic therapy in dentistry: a literature review. Clin Oral Investig 17, 1113-1125.

4. Avci P, Gupta A, Sadasivam M, Vecchio D, Pam Z, Pam N et al. (2013) Low-level laser (light) therapy (LLLT) in skin: stimulating, healing, restoring. Semin Cutan Med Surg 32, 41-52.

5. Konopka K, Goslinski T (2007) Photodynamic therapy in dentistry. J Dent Res 86, 694-707.

6. Soukos NS, Goodson JM (2011) Photodynamic therapy in the control of oral biofilms. Periodontol 2000 55, 143-166.

7. Mang TS, Tayal DP, Baier R (2012) Photodynamic therapy as an alternative treatment for disinfection of bacteria in oral biofilms. Lasers Surg Med 44, 588-596.

8. Dai T, Gupta A, Murray CK, Vrahas MS, Tegos GP, Hamblin MR (2012) Blue light for infectious diseases: Propionibacterium acnes, Helicobacter pylori, and beyond? Drug Resist Updat 15, 223-236.

9. Fontana CR, Song X, Polymeri A, Goodson JM, Wang X, Soukos NS (2015) The effect of blue light on periodontal biofilm growth in vitro. Lasers Med Sci 30, 2077-2086.
10. Konig K, Teschke M, Sigusch B, Glockmann E, Eick S, Pfister W (2000) Red light kills bacteria via photodynamic action. Cell Mol Biol (Noisy-le-grand) 46, 1297-1303.

11. Feuerstein O, Moreinos D, Steinberg D (2006) Synergic antibacterial effect between visible light and hydrogen peroxide on Streptococcus mutans. J Antimicrob Chemother 57, 872-876.

12. Steinberg D, Moreinos D, Featherstone J, Shemesh M, Feuerstein O (2008) Genetic and physiological effects of noncoherent visible light combined with hydrogen peroxide on Streptococcus mutans in biofilm. Antimicrob Agents Chemother 52, 2626-2631.

13. Feuerstein O (2012) Light therapy: complementary antibacterial treatment of oral biofilm. Adv Dent Res 24, 103-107.

14. Chebath-Taub D, Steinberg D, Featherstone JD, Feuerstein O (2012) Influence of blue light on Streptococcus mutans re-organization in biofilm. J Photochem Photobiol B 116, 75-78.

15. Gomez GF, Huang R, MacPherson M, Ferreira Zandona AG, Gregory RL (2016) Photo inactivation of Streptococcus mutans biofilm by violet-blue light. Curr Microbiol 73, 426-433.

16. Ajdic D, McShan WM, McLaughlin RE, Savic G, Chang J, Carson MB et al. (2002) Genome sequence of Streptococcus mutans UA159, a cariogenic dental pathogen. Proc Natl Acad Sci U S A 99, 14434-14439.

17. Huang R, Li M, Gregory RL (2012) Effect of nicotine on growth and metabolism of Streptococcus mutans. Eur J Oral Sci 120, 319-325.

18. Pierce CG, Uppuluri P, Tristan AR, Wormley FL, Mowat E, Ramage $G$ et al. (2008) A simple and reproducible 96 well plate-based method for the formation of fungal biofilms and its application to antifungal susceptibility testing. Nat Protoc 3, 1494-1500.

19. Gobor T, Corol G, Ferreira LE, Rymovicz AU, Rosa RT, Campelo PM et al. (2011) Proposal of protocols using D-glutamine to optimize the 2,3-bis(2-methoxy-4-nitro-5sulfophenly)-5-[(phenylamino)carbonyl]-2H-tetrazolium hydroxide (XTT) assay for indirect estimation of microbial loads in biofilms of medical importance. J Microbiol Methods 84, 299-306.

20. Berridge MV, Herst PM, Tan AS (2005) Tetrazolium dyes as tools in cell biology: new insights into their cellular reduction. Biotechnol Annu Rev 11, 127-152.

21. Ishiguro K, Washio J, Sasaki K, Takahashi N (2015) Realtime monitoring of the metabolic activity of periodontopathic bacteria. J Microbiol Methods 115, 22-26. 